\title{
Filosofia da ciência e epistemologias feministas: entrevista com Helen Longino
}

\author{
Philosophy of Science and feminist epistemologies: \\ an interview with Helen Longino
}

\author{
Prof ${ }^{\text {a }}$ Dra. Helen Longino - Department of Philosophy - Stanford University \\ hlongino@stanford.edu
}

Yasmin Leonardos Haddad - PhD Candidate, Department of Philosophy yasmin.haddad@mail.mcgill.ca

Jade Bueno Arbo - Doutoranda PPGL UFPel

jade.arbo@ufpel.edu.br

https://orcid.org/0000-0001-5726-6545

\author{
Maria Helena Silva Soares - Doutoranda PPGFIL UERJ \\ helenastraub@gmail.com \\ https://orcid.org/0000-0002-5421-2151
}

Recebido em:05/10/2021

Aceito em:22/10/2021

Helen Longino é professora emérita de Filosofia na Universidade de Stanford, onde atua desde 2005. Entre 1995 e 2005, ocupou a cadeira de Professor of Philosophy and of Women's Studies da Universidade de Minnesota. Longino possui bacharelado em literatura inglesa pelo Barnard College (1966), mestrado em filosofia pela Universidade de Sussex (1967) e doutorado em filosofia pela Universidade Johns Hopkins (1973). Seus trabalhos giram em torno das áreas de filosofia da ciência, epistemologia social e filosofia feminista. Entre 2013 e 2014 presidiu a Philosophy of Science Association. Além da publicação de diversos artigos de extrema relevância nas áreas às quais se dedica, Longino é autora dos livros Science as social knowledge: values and objectivity in scientific inquiry (1990), The fate of knowledge (2001), ganhador do prêmio Robert K. Merton Professional Award de 2002, e Studying human behavior: how scientists investigate aggression and sexuality (2013), laureado como Best Book in Feminist Philosophy Prize em 2014.

Essa entrevista ocorreu de forma remota pela plataforma Zoom, no dia 27 de julho de 2021. A professora Longino abordou sua trajetória e questões sobre valores, filosofia da ciência e epistemologias feministas. Ela analisou problemas fundamentais dessas áreas, como a objetividade e a confiabilidade da ciência, além de comentar e incentivar a formação e a pesquisa em teoria feminista. 
1- Obrigada por ter aceitado o nosso convite para essa entrevista. Acreditamos que essa será uma ótima oportunidade para que pesquisadores e pesquisadoras lusófonas possam conhecer melhor o seu trabalho. Você poderia nos contar um pouco sobre a sua trajetória e como você começou a se interessar por filosofia da ciência, e, mais especificamente na questão da ciência e valores?

Claro. Bem, primeiro gostaria de agradecer ao convite. É uma honra ter sido considerada digna de uma entrevista e espero que isso encoraje mais interações entre filósofo(a)s brasileiro(a)s e norte-americano(a)s.

Eu comecei a me interessar pela filosofia da ciência de certa forma por acaso. Eu estava cursando minha pós-graduação em filosofia [1967] com um interesse em lógica e filosofia da linguagem, durante o mestrado. Eu li um artigo por dois filósofos da linguagem e achei tão inteligente que pensei: "Hmmm, talvez seja interessante estudar com eles." Então, dentre as universidades onde fiz processos seletivos para o doutorado, uma delas era onde esses dois filósofos eram colegas e ensinavam.

Fui aceita nessa universidade [Johns Hopkins University] com uma bolsa. E, quando cheguei, descobri que um deles era um filósofo da ciência, e outro era um filósofo da matemática. Então, se eu de fato quisesse aprender algo com eles, eu teria que aprender filosofia da ciência, que era uma área que me permitiria continuar a estudar alguns interesses que desenvolvi na filosofia da linguagem. Eu tinha interesse na questão da referência. Meu interesse era na capacidade da lógica de representar linguagens naturais e inferências, que eu defendia não ser muito capaz de fazê-lo. Foi assim que me interessei pela filosofia da ciência.

Então me aprofundei na questão dos valores na ciência alguns anos depois de terminar meu doutorado, enquanto eu ensinava. Durante meu doutorado, eu tinha pensado sobre a questão da inferência e trabalhei em um artigo durante o meu pós-doutorado, que eventualmente foi publicado. O artigo era sobre a relação entre evidências e hipóteses, onde eu articulava uma versão da tese de subdeterminação na filosofia, embora não fosse algo ao qual eu havia sido exposta nos meus estudos. Eu não sabia muito que esse era o nome do problema do qual eu estava tratando, mas era isso que eu estava fazendo.

No geral, eu me interessei pelo papel do contexto no raciocínio, e, sobretudo, no raciocínio científico. Essa era uma época extremamente animadora em termos de atividades feministas, e o grupo de estudantes no campus, que estava organizando um curso que na época chamava-se "Women's studies" - não havia um curso oficial oferecido pela Universidade; esse curso era oferecido e organizado pelos estudantes - me perguntaram se eu poderia preparar uma palestra para esse curso, uma aula sobre ciência, já que eu lecionava filosofia da ciência, e sobre o que cientistas feministas falavam na época.

Havia poucas filósofas feministas nessa época [década de 70] pensando sobre a ciência. E entre as mulheres cientistas, eu via que havia uma tensão entre ideias sobre o papel de valores sexistas na ciência que elas criticavam, e como superar esses valores, e daí por diante. E foi isso que me pegou. Vi que todo o meu trabalho filosófico sobre contexto e pressuposições de fundo (background assumptions) no raciocínio poderia ser uma intervenção útil. Foi assim que os interesses se uniram, e foi assim que começou.

2- Nossa segunda pergunta é sobre a educação moderna. E um dos paradigmas da educação moderna é que os currículos científicos e filosóficos estão se tornando cada vez mais especializados. Como essa tendência afeta as abordagens pluralistas da ciência?

Bem, meu antigo colega, o falecido Patrick Suppes, escreveu sobre pluralismo científico por volta de 1980. Ele fez um discurso para a Associação de Filosofia da Ciência (Philosophy of Science Association) sobre isso, com base nesse próprio fato da especialização. Ele basicamente dizia que as ciências estavam se tornando tão especializadas que os pesquisadores de uma subdisciplina não conseguiam entender o que os pesquisadores de outra subdisciplina estavam fazendo. Não havia garantia de que eles sequer estivessem falando sobre a mesma coisa.

Por isso, o que tínhamos nas ciências era apenas uma pluralidade de diferentes disciplinas, diferentes metodologias, diferentes vocabulários, todos tentando lidar com o que consideramos ser nosso mundo comum. E acho que ainda é assim que a multiplicidade de subdisciplinas afeta as abordagens pluralistas. 
Na ciência, há certa esperança, por parte de alguns cientistas, de que eventualmente haja uma "teoria de tudo", capaz de abranger tudo o que pensamos que sabemos agora - ou pelo menos todos os domínios sobre os quais nós fazemos ciência agora, mas, é claro, de forma unificada.

Isso é uma esperança, um ideal. Mas acho que fica cada vez menos provável, apenas pensando empiricamente sobre o caráter das ciências, que esse seja um ideal que algum dia atingiremos. Acho que é um ideal que ainda é útil porque motiva a interação crítica entre diferentes abordagens, porque quando eu acho que estou tentando chegar ao que é a visão unificada correta, e você acha que está tentando chegar ao que você acha que é a visão unificada correta, e temos ideias diferentes, então, vamos nos envolver uns com os outros.

Acho que a ideia de uma ciência unificada é útil nesse sentido, mas não é útil filosoficamente. Porque quando é usada filosoficamente, tende a ser usada como um critério epistemológico. E isso, eu acho, é muito nocivo. Acho que a divisão em subespecialidades realmente apoia a ideia de abordagens pluralistas, mas acho que provavelmente temos uma maneira ainda mais agravada de pensar sobre isso do que o falecido Patrick Suppes tinha: ele apenas falava sobre a incompreensibilidade mútua de diferentes subespecialidades.

O que muitos filósofos têm examinado mais cuidadosamente são as maneiras pelas quais cientistas que pensam sobre o mesmo fenômeno podem ter maneiras diferentes, mas igualmente bem-sucedidas, de investigar esse fenômeno. E a abordagem a ser adotada vai depender de propósitos particulares para se engajar na investigação em primeiro lugar.

Acho que hoje temos uma compreensão um pouco diferente da que Suppes tinha sobre o pluralismo, mas Suppes foi o primeiro a falar disso.

3- Um dos principais pontos de tensão em teoria feminista tem sido o seu sujeito. Muito já foi escrito no campo dos estudos feministas sobre a definição de "mulher" e seu estatuto de fundação do feminismo e a base para reivindicações feministas. Na sua visão, como os debates sobre o sujeito o qual o feminismo deve representar se manifestaram no campo da epistemologia feminista desde os anos 1990?

Primeiro, vou mencionar algo da minha própria análise sobre a questão, e em seguida mencionarei algo histórico. Também acredito que isso tenha a ver com uma questão linguística e esteja relacionada ao vocabulário de línguas diferentes.

A meu ver, o feminismo é sobre gênero e as diferenças de gênero, e não apenas sobre a mulher. É claro que há trabalhos feministas que focaram exclusivamente na questão da mulher, como esse termo é entendido pelos falantes [de uma língua].

O mesmo acontece na epistemologia. Por exemplo, entre psicólogos e filósofos, houve um interesse talvez antes dos anos 1990 - nos modos de conhecer das mulheres, e, por exemplo, na ideia de que a mulher traz uma consciência distinta nas suas percepções do mundo e na sua compreensão do mundo (seja por causa de experiências distintas ou por algum outro motivo).

Isso, é claro, foi criticado como sendo essencialista e problemático pois falhava em atribuir diferenças entre mulheres. A partir do momento que se defende que todas as mulheres têm esse ponto de vista, diferenças importantes entre mulheres são ignoradas e assume-se que todas as mulheres têm a mesma experiência. $\mathrm{E}$ isto não é o caso. Este certamente é um dos debates que influenciou a epistemologia feminista.

Acredito que existem duas questões aqui: a primeira diz respeito a se podemos falar em alguma experiência, a experiência das mulheres, como sendo distinta da experiência dos homens, e que seja universal entre as mulheres se forma a ser a base para a teorização feminista em diferentes disciplinas; a segunda diz respeito à possível existência de similaridades ou de alguma unidade da experiência de forma que possamos pensar as mulheres como uma única categoria sobre a qual construir qualquer tipo de teorização.

Houve os modos de conhecer das mulheres e versões iniciais da teoria do ponto de vista que pressupunham a existência de algumas experiências universal das mulheres que concederiam a elas uma perspectiva 
distinta sobre o mundo capaz de embasar suas teorizações sobre o mundo. Um exemplo é a cientista política Nancy Harstock ${ }^{1}$, que deliberadamente tomou do marxismo a ideia de um ponto de vista, transformando-o da perspectiva (standpoint) que alguém adquire em relações de produção para a que se adquire em relações de reprodução, e desenvolveu as ideias iniciais sobre um ponto de vista feminista.

Inicialmente, então, havia essas formas de pensar sobre a questão, e a teoria do ponto de vista, em suas formulações iniciais, presumia certa singularidade ao sujeito feminino, com experiências semelhantes que pudessem embasar a teorização feminista. E, novamente, isso foi desfeito pelo reconhecimento de diferenças entre mulheres, diferenças de classe social, na experiência econômica, nas experiências raciais. Uma vez que essas diferenças foram reconhecidas, então essa ideia do sujeito feminino único precisava cair por terra

E, então, é claro, temos o seguinte problema: “do que exatamente estamos falando?”. E vemos aí uma razão para pensar por que seria útil pensar em termos do sujeito da teoria feminista como sendo o tema da diferença de gênero. Ou seja, as maneiras pelas quais percepções de gênero, ou percepções da diferença de gênero, são usadas para estabelecer diversas formas de diferenças sociais e econômicas. E essas diferenças são também marcadas por diferenças raciais e de classe.

Esse é o primeiro ponto. O segundo ponto é: como podemos pensar isso em relação à epistemologia feminista? Uma das minhas propostas é que, independentemente das normas epistêmicas de cada um, nós buscamos, enquanto feministas, escolher, selecionar e depender de normas epistêmicas que ou auxiliam a tornar o gênero visível, ou, ao menos, que não façam com que o gênero desapareça das análises.

É claro que isso é uma noção muito abstrata e que não especifica quais metodologias ou normas deveriam ser implementadas. Mas acredito que isso esteja certo, pois nossas metodologias e normas devem ser sensíveis ao campo de estudo que estamos investigando. É ao longo de uma investigação de fato que essas questões se tornam importantes.

E haverá normas diferentes que serão relevantes para investigações diferentes. Talvez vocês conheçam minhas publicações sobre a relação e a diferença entre valores cognitivos tradicionais valores feministas. Eu diria o mesmo, como já o disse, sobre os chamados valores feministas: tais valores permanecem valores na medida em que promovem esse objetivo de evitar que a diferença de gênero desapareça das análises, ou tornar o gênero visível nas instâncias em que ele existe. Mas isso não significa que tais valores sejam sempre feministas, pois o contexto pode mudar, as coisas podem mudar.

4- No Brasil, parece haver uma espécie de tensão na teoria feminista entre reconhecer a diferença e buscar a equidade. Há certo reconhecimento de que uma ideia ontológica de mulher não é, necessariamente, a base para o feminismo e para a teorização feminista, mas por vezes a teoria feminista parece entender que a falta desse sujeito pode trazer algum tipo de relativismo às reivindicações feministas. Você poderia falar sobre isso e sobre o que são esses valores feministas?

HL: Acho que é importante ter em mente que muito do que consideramos ser diferença sexual ou diferença de gênero é construído. Isso não significa que não seja vivenciada pelas pessoas que vivem em tempo real, mas que é uma função do ambiente social em que vivemos, da língua que falamos, dos mitos com os quais crescemos. Todos eles trazem diferença de gênero e poder profundamente infundidos por meio deles, de modo que se torna uma maneira quase natural de ver o mundo através dessas lentes de gênero, que também são lentes de diferenciação de poder. Mas essas são, em grande parte, uma função da história e da história da sociedade.

Então pensar que o que experimentamos agora como diferenças entre mulheres e homens representa qualquer tipo de realidade ontológica profunda me parece muito equivocado, muito negligente com a história e provavelmente nos levará a becos sem saída.

$1 \quad$ Nancy Harstock (1943-2015) foi professora de Ciência Política e Estudos da Mulher na Universidade de Washington de 1984 a 2009 e é uma das precursoras da teoria do ponto de vista (standpoint theory). 
Em segundo lugar, ser igual não é o mesmo que igualdade, ser igual e igualdade não são a mesma coisa. Igualdade é um conceito legal, e envolve alguém ser tratado pela lei de forma igual, significa que todos os sujeitos são tratados da mesma forma pela lei. Isso é o que significa igualdade. Ser igual significa ser igual, e, claro, ninguém é igual a ninguém. Há certos tipos de diferenças óbvias que tornam diferentes grupos de pessoas diferentes de outros grupos de pessoas, mas isso não tem qualquer influência sobre seu estatuto legal. Então, acho que tentar descobrir, por exemplo, as maneiras pelas quais mulheres e homens realmente são iguais de alguma forma, e isso é o que fundamentaria nossa reivindicação de igualdade... Isso nunca vai funcionar, porque as diferenças continuam sendo impostas e recolocadas e reescritas de maneiras diferentes pelas estruturas sociais em que estamos, então ser igual não é um fundamento para uma reivindicação de igualdade.

Pois bem, mas o que é que fundamenta uma reivindicação de estatuto legal por parte de um sujeito? Certas capacidades, as capacidades, em uma democracia, que fundamentam o direito ao voto, o direito ao governo de si. Todos os esforços que foram feitos para tentar mostrar que as mulheres são menos capazes de governarem a si mesmas - podemos pensar em toda aquela biologia maluca do século 19 e do século 20 , por exemplo - tudo isso é apenas ciência ruim. Acima de qualquer coisa, isso é ciência ruim. Geralmente é baseada em dados e estatísticas ruins, então podemos simplesmente jogá-la fora. Não é teoricamente interessante. É simplesmente ruim.

Portanto, nada que tente mostrar que há alguma diferença inerente realmente funciona. Nesse caso, o padrão deveria ser que, salvo que se prove o contrário, todos nós temos a mesma capacidade de raciocinar e pensar que subscreve nosso direito ao voto. Portanto, participar igualmente na governança de nós mesmos e da nossa sociedade: isso é o que significa votar. Unidos.

Desculpe, votar é um grande problema para mim agora, por causa do que está acontecendo nos Estados

Vou apenas falar rapidamente sobre este trabalho que fiz sobre valores na ciência ${ }^{2}$. Existe um conjunto de valores que são geralmente propostos como valores epistêmicos, e diferentes filósofos da ciência têm recorrido a eles para diferentes tipos de trabalho em momentos diferentes. Thomas Kuhn recorre a um conjunto de valores como sendo aqueles que fazem com que a ciência supere a aparente incomensurabilidade da qual ele fala por meio de paradigmas e assim por diante.

Outros filósofos falaram sobre esses valores como o que os cientistas usam em casos de subdeterminação, quando são incapazes de escolher entre teorias com base em evidências, e os valores são os seguintes: há 1) adequação empírica, mas todos se preocupam com isso; 2) consistência, consistência interna e consistência externa; 3) simplicidade, 4) poder explicativo e o último, às vezes é chamado de 5) testabilidade, é a capacidade de gerar consequências empíricas. Kuhn fala em termos de fecundidade, onde fecundidade significa a capacidade de gerar problemas nos quais os pesquisadores possam trabalhar.

Portanto, esses são os valores convencionais e tradicionais. Quando eu olhei para o trabalho de cientistas feministas, eu as vi defendendo ou exibindo o uso de um conjunto diferente de valores que estavam curiosamente relacionados a esses valores cognitivos padrão. Claro, todo mundo quer a adequação empírica, mas a adequação nunca é suficiente por muitos motivos que não vou entrar em detalhes aqui.

As feministas estavam interessadas em novas ideias, porque queriam coisas que desafiassem o pensamento patriarcal, o pensamento sexista. Elas não estavam interessadas na consistência com a teoria existente, porque usá-la como um padrão pode limitar os tipos de reflexão que poderia ser feito - portanto, inovação. Elas também estavam interessadas ou valorizavam preservar a heterogeneidade relevante em suas amostras, porque havia muitas delas que estavam trabalhando em etologia com populações animais - a primatologia é um grande exemplo disso - e estavam interessadas em olhar para as diferenças no comportamento de animais fêmeas e machos na população, ao passo que, em trabalhos anteriores, os machos da população foram

2 LONGINO, H. Valores, heurística e política do conhecimento. Scientiae Studia, [S. 1.], v. 15, n. 1, p. 39-57, 2017. DOI: 10.11606/51678-31662017000100003. Disponível em: https://www.revistas.usp.br/ss/article/view/133642. Acesso em: 15 out. 2021. 
considerados representativos da população como um todo e, portanto, o que quer que as fêmeas fizessem era simplesmente ignorado. Quando as mulheres pesquisadoras olharam para as fêmeas encontraram padrões realmente interessantes de interação social, e descobriram que as mulheres exerciam mais poder na sociedade do que os primatologistas acreditavam anteriormente.

Isso significa que você não acha que todos os animais da população são iguais, você presta atenção às diferenças entre os animais da população, presta atenção às diferenças em sua amostra, em vez de tentar enfatizar a uniformidade, digamos, encontrando os valores médios: você tentará procurar diferenças significativas na população - portanto, heterogeneidade.

Outro valor que encontrei foi um destaque da complexidade, olhar para a complexidade das interações em oposição às relações causais lineares. Portanto, tentava-se evitar algo como "a molécula mestre" para pensar sobre os fenômenos biológicos e, em vez disso, olhava-se para as maneiras como as entidades em um processo biológico estavam interagindo, sem procurar um agente que estava causando todos os outros tipos de mudanças que aconteciam em um processo. Era uma maneira realmente diferente de entender o processo.

Tanto a complexidade quanto a heterogeneidade têm sido conceitos muito profícuos entre as pessoas que os defendem, porque existem tantos tipos diferentes de simplicidade. Então, de que tipo de simplicidade está se falando? Mas também deixaremos isso de lado.

Em vez de coisas como "ter consequências empíricas" ou "fecundidade", as feministas defenderam um tipo de direção de aplicação, a aplicabilidade às necessidades humanas, e uma predileção por modelos e representações que distribuíam poder, difundiam poder, em vez de tentar representar fenômenos como sujeitos ao exercício do poder humano, ou como sujeitos a relações de poder internamente em determinada área. Isso me pareceu muito interessante. Eu escrevi sobre isso algumas vezes, que havia esses valores alternativos, e eu acho que eles são valores que também podem informar os cientistas ambientais, não apenas a ciência feminista, então, eles não são apenas distintamente feministas. O que pode dar a eles o status de valores feministas é sua capacidade, como disse, de evitar que o gênero seja apenas diferença de gênero e que a diferenciação de gênero seja ocultada na área a ser investigada.

\section{5- Na sua visão, de que forma as epistemologias feministas podem contribuir para o nosso enten- dimento da objetividade na ciência?}

A resposta depende, em parte, de quais epistemologias feministas estamos falando. Algumas formas de feminismo empirista defendem essencialmente o fato de que a boa ciência é objetiva, independentemente do que isso significa. Então, a contribuição epistêmica é a de mostrar que muito da ciência existente foi influenciada por valores sexistas, estereótipos sexistas, pelo pensamento patriarcal, e assim por diante. Algumas epistemologias feministas são de fato uma plataforma para criticar a ciência existente.

Mas outras epistemologias feministas estão realmente interessadas no tipo de estrutura do conhecimento e na estrutura do conhecimento científico em si. A estrutura do conhecimento é tal que o que, à primeira vista, identificaríamos como valores ou preocupações não-epistêmicas, ideologias ou visões metafísicas profundas, desempenha um papel na interpretação dos dados que são coletados.

Epistemologias feministas também são importantes de outra maneira: elas chamam a atenção para a forma como a coleta de dados em si é problemática, pois o que tomamos como um traço do mundo a ser explicado é em si uma função dos nossos valores. Nós podemos tentar ser neutros em termos de valores na nossa explicação daquele traço do mundo, mas se a nossa seleção daquele traço do mundo como algo que queremos analisar é uma função dos nossos valores, então os valores estão lá desde o início. Acredito que uma das coisas que as epistemologias feministas fizeram é mostrar a forma pela qual a seleção dos traços do mundo a serem explicados, a serem compreendidos, refletem eles mesmos os valores daqueles que fazem pesquisa. O exemplo mais claro disso é a biomedicina, é claro, onde modelos animais que são usados para pensar sobre fisiologia - exceto quando estão analisando fisiologia reprodutiva - tendem a ser modelos 
masculinos, e aí as medicações são desenvolvidas para os homens europeus padrão. Quando cirurgias são criadas, enfim... Tudo é desenvolvido para os homens europeus padrão, e não apenas mulheres, mas pessoas de outras raças possuem diferenças fisiológicas ou estruturais.

Então, como as epistemologias feministas podem contribuir para o nosso entendimento da objetividade? Primeiramente, elas contribuem ao mostrar que o que temos tomado como exemplos de objetividade podem não sê-lo, de fato. Da mesma forma, o que epistemologias feministas e intervenções feministas fizeram foi mostrar que nós realmente precisamos pensar sobre essa objetividade, o que nós queremos dizer com "objetividade". Que tipo de critério constitui objetividade? Certamente essa é uma das contribuições das epistemologias feministas.

Além disso, feminismos diferentes tiveram ideias diferentes sobre objetividade. Alguns deles pensaram que a objetividade é algo como neutralidade de valor enquanto outras pensaram que não existe neutralidade de valor, então devemos pensar sobre os valores que estamos trazendo, ou que um outro pesquisador traz para a pesquisa, e discutir sobre esses valores e não apenas sobre os dados, assumindo que os dados falam por si mesmos de alguma forma.

\section{6- E de que forma a falta de um padrão ouro para a objetividade científica afeta a desconfiança geral na ciência, como a que testemunhamos nos últimos dois anos?}

Penso que a desconfiança geral na ciência se baseia em expectativas exageradas na ciência, e isso tem sido apoiado pela própria comunidade científica. Ou seja, "Sim, nós temos as respostas, nós sabemos, então apenas ouça-nos". E uma vez que você começa a prestar atenção em como a ciência funciona, e como os cientistas falam quando não estão falando com o público, quando estão conversando entre si, nós vemos que os cientistas e pesquisadores entendem que eles não são infalíveis. Não é apenas que os pesquisadores cometem erros, é que os pesquisadores só podem ir tão longe quanto os dados permitirem. E, é claro, os dados serão interpretados à luz de suposições de fundo. Assim, os pesquisadores só podem ir tão longe quanto seus dados e suas suposições de fundo permitirem, e é o que Duhem nos mostrou: pode haver a insuficiência nos dados ou pode haver uma insuficiência nas suposições de fundo. Parte do problema, a meu ver, é que uma das maneiras como a ciência é ensinada aos jovens durante todo o ensino médio e, nos anos iniciais da universidade, é como um conjunto de fatos que eles devem memorizar, que eles têm que saber, e isso está estabelecido, está acima de qualquer dúvida, não pode ser criticado, o que é uma forma terrível de ensinar ciência.

Ciência é sobre engajamento e crítica, um passo à frente e um passo atrás. A história da ciência é uma história tanto de erros e ideias abandonadas quanto de ideias, técnicas e tecnologias que foram transmitidas às gerações seguintes. Acho que qualquer pesquisador vai lhe dizer que não existe certeza; mas é isso que esperamos, como público, da ciência. E então é daí que vem a desconfiança na ciência, acredito, especialmente no último ano [2020], pelo menos nos Estados Unidos.

Os pesquisadores estavam trabalhando com poucos dados positivos no início. Por exemplo, se as máscaras são úteis ou não, ou se deveríamos usar luvas o tempo todo ou não. Devíamos lavar as mãos toda vez que tocamos uma superfície? Quer dizer, todas essas coisas que eram precauções baseadas em parte em não saber realmente o que era o vírus, as propriedades do vírus, como ele era realmente transmitido de uma pessoa para outra - e, na verdade, o vírus não dura muito nas superfícies. Então isso não é um problema: você não precisa lavar suas compras quando chega em casa, que é o que algumas pessoas estavam fazendo. Não sei se vocês viram no Brasil, mas havia vídeos com instruções elaboradas sobre como lavar todas as suas compras quando chegava em casa. Muito louco.

Portanto, a orientação foi baseada no que os pesquisadores sabiam com base na experiência anterior com vírus respiratórios, mas sem muito conhecimento sobre o SARS-CoV-2. Então eles mudaram suas orientações à medida que aprenderam mais. Se o público em geral não tem uma compreensão de que a ciência é orgânica, que o conhecimento científico é como um corpo orgânico de conteúdo dinâmico e crescente, que muda conforme os pesquisadores interagem com os dados à medida em que eles coletam mais dados ao procurar 
padrões diferentes... Por isso é claro que, quando os pesquisadores dizem "bem, pensamos que era isso, agora pensamos que é isso", ou se eles nem mesmo colocaram dessa forma, isso alimenta a desconfiança. Acho que parte do que explica a desconfiança do público na ciência e não apenas durante a pandemia, mas também no que diz respeito ao clima - embora essa questão da mudança climática seja um pouco mais complicada -é uma falha do ensino de ciências: não ensinar as pessoas a esperar esse tipo de coisa.

A ciência não é o domínio da certeza, a ciência é o domínio da investigação, onde você está sempre aprendendo mais, sempre mudando de ideia. E é um lugar de dinamismo, não de paralisia, e da forma como é ensinado, é ensinado como um lugar de paralisia: aqui estão os fatos 1, 2, 3 e 4.

Acho que não temos um padrão-ouro para a objetividade científica, em parte, porque não temos um tipo geral de compreensão compartilhada de como a investigação funciona. E se tivéssemos um entendimento comum de como a investigação funciona? Bem, eu acho que é possível ter padrões de objetividade que funcionem para uma espécie de avaliação pública sobre a confiabilidade da ciência, mas deve ser nesse contexto em que não se espera a certeza, onde objetividade não significa o mesmo que certeza. Objetividade tem a ver com confiabilidade, mente aberta e outras propriedades da pesquisa, abertura para críticas e os tipos de coisas sobre as quais falei em meus livros.

Se entendermos a objetividade como uma propriedade das comunidades de pesquisa, então acho que podemos pensar sobre como as comunidades de pesquisa funcionam, e isso é algo que o público pode avaliar quando estiver tentando decidir se segue, digamos, o Painel Internacional sobre Mudanças Climáticas em oposição a algum negacionista, ou tentando decidir se segue o que um profissional de saúde pública diz em oposição ao que um político diz. No caso de uma pandemia, você pode olhar para as comunidades nas quais essas pessoas estão inseridas e das quais falam para ter uma ideia de quais são mais prováveis de serem fontes confiáveis de informação.

\section{E eu acho que o que acontece nos Estados Unidos foi ampliado no Brasil com o negacionismo.}

Sim, nós tivemos notícias. Isso me deixa muito triste. Mas há muito disso em todo o mundo. Brasil e Estados Unidos são exemplos bastante extraordinários, mas não estamos sozinhos.

\section{7- A pandemia do COVID-19 trouxe uma nova onda de negacionistas, exacerbando o sentimento anticientífico do público em geral. Quais desafios as epistemologias feministas e a filosofia da ciência enfrentam quando se trata de combater a ameaça do relativismo generalizado?}

Acredito que possa ser tentador voltar à posição original de certeza para nos defendermos contra o relativismo, mas também acredito que seja muito mais importante reconhecê-lo. Digo, existem tipos diferentes de relativismo. $\mathrm{O}$ que queremos dizer quando dizemos que alguém é relativista? A acusação de relativismo já é suficiente para que se queira voltar a uma posição filosófica absolutista, mas acredito que isso seja um equívoco. A melhor abordagem é a de dizer “Bem, de qual tipo de relativismo estamos falando?". Certamente numa visão pluralista, compreendemos que resultados são uma função de instrumentos que estejam sendo usados, pressuposições de fundo que enquadram uma investigação, estratégias de medição... Então sim, os resultados são relativos a todos esses aspectos. Mas se é isso que você quer dizer com relativismo, eu não estou preocupada.

Mas alguns interpretam o relativismo como uma postura segundo a qual seria possível acreditar no que quiséssemos. E claro, sim, você pode acreditar em qualquer coisa que quiser, mas as ideias propostas por filosofias pluralistas da ciência não justificam acreditar em simplesmente qualquer coisa. São ideias relativistas na medida em que reconhecem que os resultados são uma função de um tipo de contexto científico formado por suposições, por tecnologias de medição, por instrumentos, e assim por diante. Portanto, é claro, os resultados vão mudar quando as tecnologias de medição, os instrumentos, as suposições de fundo mudarem, o que não os torna menos importantes no momento em que são produzidos. Isso só significa que, dentro de uma estrutura maior, há um certo tipo de progresso. 
Nesse sentido, defendo, assim como Kuhn, em pensar que não há um movimento linear na direção da "teoria de tudo" de Steven Weinberg procurava. Acho que o relativismo é uma espécie de ofensa que acena ao pluralista ou ao contextualista para dizer: "Olha onde você vai nos levar agora, a este 'vale tudo"'. Isso não é verdade. Sendo assim, acho que distinguir entre diferentes tipos de relativismo é realmente importante.

\section{8- Então, quais são os principais desafios para as epistemologias feministas hoje? Como eles diferem daqueles do século $\mathrm{XX}$ ?}

Acho que provavelmente existem diferentes desafios para diferentes epistemologias feministas, mas uma área que tem recebido muita atenção, na qual tenho certeza de que vocês também têm pensado, é toda essa área de injustiça epistêmica e em ideias que foram apresentadas pela primeira vez por Miranda Fricker, mas que outras pessoas também discutem.

Acho que o que as feministas estão fazendo atualmente em epistemologia é desenvolver essas ideias de injustiça epistêmica, e associado a isso uma outra forma de injustiça epistêmica, que é algo como uma ignorância voluntária, ou seja, a compreensão da ignorância como um fenômeno a ser investigado epistemologicamente. Isso representa, a meu ver, um tipo de compreensão mais sofisticada dos modos sutis de dominação que são exercidos na sociedade e as maneiras pelas quais os comportamentos individuais reforçam estruturas sociais injustas.

De certa forma, isso é uma espécie de virada para a prática, ao passo que a epistemologia feminista, digamos, no século 20, estava possivelmente mais interessada em tentar encontrar um fundamento teórico. Acho que parte do trabalho que conheço agora está muito mais focado menos em uma fundamentação teórica e mais em uma espécie de identificação de práticas que se enquadram no âmbito da epistemologia, mas que participam da perpetuação de estruturas sociais injustas. Por exemplo, padrões de interrupção - tenho certeza de que todas nós já passamos por isso -, padrões de atribuição e falha de atribuição - nós quatro já passamos por isso, com certeza -, Interpretação errônea, a insistência em traduzir uma determinada representação em uma linguagem que neutralize a injustiça da situação que ela tenta descrever... Essas são todas formas de injustiça epistêmica. E estão realmente focando em formas de interação de nível muito micro de perpetuação de estruturas injustas.

Acredito que a diferença que a epistemologia feminista pode fazer, da forma como eu penso sobre ela, é no "pensar como uma feminista" e a diferença que faz na filosofia.

\section{9- Você poderia nos falar um pouco sobre os seus projetos mais recentes e atuais interesses de pesquisa?}

Sobre o projeto no qual tenho trabalhado, tenho um artigo que sairá em breve. Tenho trabalhado para realmente esclarecer a diferença entre a minha forma de epistemologia social e a epistemologia social dominante, que eu acho que ainda é muito individualista. Por isso, tenho alguns artigos com esse objetivo.

E o grande projeto no qual estou trabalhando é um projeto sobre interações. Acho que a interação é pouco estudada filosoficamente. Por exemplo, interação normalmente se refere a objetos e indivíduos e assim por diante, mas acho que as interações desempenham um papel tão importante no mundo quanto entidades individuais. As interações são, em nossa teorização, frequentemente apagadas em favor de ações individuais, por isso quero elevá-las a um status ontológico equivalente ao status ontológico dos indivíduos em nossa teorização, pensando nas interações, como são descritas em várias ciências. A biologia é o exemplo mais óbvio e há muitos tipos diferentes de interações na biologia, mas existem interações na física também, obviamente. Há também interações nas ciências sociais. E então, quando passamos à filosofia, minha maneira de pensar sobre o conhecimento é que minha epistemologia é sobre interação, e esses padrões epistêmicos, conceitos epistêmicos, que emergem através das interações sociais e se consolidam com o tempo, mas também são modificados no decorrer das interações. Portanto, vou dizer algo geral 
sobre interação, classificar as interações - o que as fará filosoficamente respeitáveis - fazer uma tipologia das interações. Esse é o projeto.

\section{0- Nós três somos estudantes de pós-graduação e queríamos saber que tipo de conselho você daria a três jovens filósofas?}

Acho que existem vários tipos de conselhos. O primeiro parece que vocês já começaram, que é encontrar colegas com quem vocês possam conversar, mas que também possam criar uma comunidade intelectual com vocês. Acho que isso é o mais importante. Quando eu era uma jovem professora assistente, a Society for Women in Philosophy estava começando a se formar nos Estados Unidos. Esse foi um contexto muito importante, para mim, como uma jovem filósofa, apenas estar com outras mulheres. A divisão do Pacífico não se limitava a filósofas que faziam filosofia feminista, era realmente um lugar para as mulheres da filosofia se reunirem e falarem sobre o trabalho que estavam fazendo como filósofas. Muitas estavam perseguindo projetos feministas, mas muitas não. Elas estavam apenas perseguindo projetos no tipo de filosofia que estavam fazendo. E esse foi um contexto realmente favorável para estar, em contraste realmente bom com locais mais ortodoxos como a American Philosophical Association. Então eu acho isso importante: desenvolver relacionamentos e círculos de amizade entre si, entre vocês.

Acredito que outro conselho é que existem vários outros objetivos que uma pessoa pode ter. Portanto, acho importante ter clareza sobre por que vocês estão fazendo o que estão fazendo, ou porque estamos fazendo o que estamos fazendo. Porque certamente existem muitas ocasiões para desânimo, maneiras de desencorajar as mulheres de seguir qualquer tipo de vida intelectual. E definitivamente há maneiras de desencorajá-las a seguir ideias feministas. Isso ainda é muito forte na filosofia. Portanto, acho importante reconhecer que esse é o mundo em que vivemos e acreditar que o trabalho que vocês estão fazendo vale as lutas que vocês estão enfrentando, e que, com o apoio de outras feministas, vocês acabarão tendo sucesso. Mas tem sido uma luta para mim e na minha carreira, e lamento que ainda seja uma luta para as estudiosas mais jovens. Isso só mostra que é uma longa luta, mas vale muito a pena. 